Midwifery, Mr. Swayne and Mr. Hetling.

Botany, Mr. Rootsey and Dr. Carpenter.

Forensic Medicine, Mr. Fairbrother and Mr. Staples.

Chemical Toxicology, Mr. Herapath.

Not being favoured with a prospectus from the Bristol School, we have been compelled to borrow this meagre account from our advertising columns.

\section{BIRMINGHAM SCHOOL.}

General and Surgical Anatomy, Mr. Sands Cox; daily, at 2 P.M.

One Session, $£ 55 s$.

Unlimited, £9 9s.

Descriptive Anatomy, Physiology, and Demonstrations, Mr. Parker and Mr. Bolton; daily, 8 A.M. One Session, $£ 33 s$.

Unlimited, $£ 66 s$.

Materia Medica, Mr. J. Johnstone and Mr. Knowles; Monday, Wednesday, Saturday, 3 P.м. One Session, $£ 44 s$.

Unlimited, $£ 66$ s.

Chemistry, Mr. Woolrich ; daily, 12 A.M.

One Session, $£ 44 s$.

Unlimited, $£ 66 s$.

Organic Chemistry, Dr. Percy. $£ 22 s$.

Practice of Physic, Dr. Eccles; Tuesday, Thursday, and Friday, 4 P.M.

One Session, $£ 44 s$.

Unlimited, $£ 77 \mathrm{~s}$.

Surgery, Mr. Sands Cox; Tuesday, Thursday, and Saturday, 6 P.M.

One Session, £3 $3 s$.

Unlimited, £5 $5 s$.

Ophthalmic Surgery, Mr. Middlemore.

Midwifery, Dr. Ingleby and Mr. Berry; Monday, Tuesday, and Friday, 6 P.M.

One Session, £3 $3 s$.

Unlimited, $£ 66 s$.

SUMMER SESSION.

Forensic Medicine, Dr. Davis; daily, 8 A.M. One Session, $£ 33 s$.

Unlimited, $£ 44 \mathrm{~s}$.

Hygiene, Dr. Melson.

Botany, Mr. Knowles; daily, 4 P.M.

One Session, $£ 33 s$.

Unlimited, $£ 44 s$.

Comparative Anatomy, Mr. Parker. Mathematics, Rev. W. M. Lawson. Natural Philosophy, Dr. Melson. Fee, for all the Courses, 40 guineas.

\section{Quenn's Hospital.}

Physicians, Dr. Davies, Dr. Percy, and Dr. Melson. Surgeons, Mr. Sands Cox, Mr. Knowles, and Mr. Parker.

\begin{tabular}{llr}
\multicolumn{3}{c}{ Medical Practice. } \\
Six months, & $£ 5$ & $5 s$. \\
Twelve months, $£ 10$ & $10 s$. \\
Perpetual, & $£ 12$ & $12 s$. \\
Surgical Practice. \\
Six months, & $£ 10$ & $10 s$. \\
Twelve months, $£ 16$ & $16 s$. \\
Perpetual, & $£ 21$ & $5 s$.
\end{tabular}

The medical officer attends daily at 8 A.M. in summer, and 9 A.M. in winter.

The following are the regulations respecting medical education, which have been issued by the College of Surgeons, Apothecaries' Hall, and University of London :-

\section{COLLEGE OF SURGEONS.}

I. Candidates will be required, in addition to a Certificate of being not less than twenty-one years of age, to bring proof-

1. Of having been engaged in the acquirement of professional knowledge during a period of not less than four years, six months of which shall have been occupied in the study of Practical Pharmacy, six months by attendance on the Practice of Physic, and the remainder of the period on the Practice of Surgery, at a recognised Hospital or Hospitals in the United Kingdom;*-three months being allowed for a vacation in each year.

2. Of having studied Anatomy and Physiology, by attendance on Lectures and Demonstrations, and by Dissections, during the three Anatomical Seasons or Sessionst :-and of having attended at least two Courses of Lectures on the Principles and Practice of Surgery, delivered in two distinct periods or seasons, each ccurse comprising not less than 70 Lectures:-and one course of not fewer than 70 Lectures, on each of the following subjects, viz. the Practice of Physic-ChemistryMateria Medica-and Midwifery, with Practical Instruction.

II. Members and Licentiates in Surgery of any legally constituted College of Surgeons in the United Kingdom, and Graduates in Surgery of any University requiring residence to obtain degrees, will be admitted for examination on producing their diploma, license, or degree, together with proofs of being twenty-one years of age, and of having been occupied at least four years in the acquirement of professional knowledge.

III. Graduates in Medicine of any legally constituted College or University requiring residence to obtain degrees will be admitted for examination on adducing, together with their diploma or degree, proof of haring completed the anatomical and surgical education required by the foregoing Regulations.

IV. Certificates will not be recognised from any hospital, unless the surgeons thereto be members of one of the legally constituted Colleges of Surgeons in the United Kingdom; nor from any School of Medicine or Midwifery, unless the respective teachers be members of some legally constituted College of Physicians or Surgeons in the United Kingdom; nor from any School of Anatomy or Surgery in England, unless the respectire teachers be members of some legally constituted College of Physicians or Surgeons in the United Kingdom, and have undergone a second or

* By a resolution of the Council on the 7th of November, 1839, no Provincial Hospital will in future be recognised by this College which contains fewer than 100 patients, and no metropolitan hospital which contains fewer than 150 patients.

$\dagger$ An Anatomical Session is understood to extend from October to April inclusive, and to comprise at least 140 Lectures on Anatomy and Physiology, occupying not less than one hour each, given on separate days; and at least 100 Demonstrations of the like duration, given in a similar manner; exclusive of Dissections, of which distinct certiticates are required. 
special examination on those branches of science, according to the ordinances of this college relating thereto.

V. Certificates will not be received on more than one brance of science from one and the same lecturer; but Anatomy and Physiology-Demonstrations and Dissections-will be respectively considered as one branch of science.

N.B. In the certificates of attendance on hospital practice and on lectures, it is required that the dates of commencement and termination may be inserted in words at length.

Blank forms of the required certificates may be obtained on application to the secretary, to whom they must be delivered, properly filled up, ten days before the candidate can be admitted to examination; and all such certificates are retained at the College.

$$
\begin{aligned}
& \text { By order of the Council, } \\
& \text { Enulido Benfocr, Sec. }
\end{aligned}
$$

August 20, 1839.

\section{SOCIETY OF APOTHECARIES,}

$$
\text { April 23, } 1835 .
$$

Every candidate for a certificate to practise as an apothecary will be required to produce testimonials-1. Of having served an apprenticeship of not less than five years to an Apothecary;2. Of having attained the full age of 21 years;3. And of good moral conduct. Students whose attendance on lectures shall commence on or after the 1st of October, 1835, will also be required to produce proof of having attended, during three winter and two summer sessions, lectures in the following order, and medical practice from the commencement of the second to the termination of the third winter session.

The Winter Medical Session is to be understood as commencing on the lst of October, and terminating in the middle of April, with a recess of fourteen days at Christmas; the summer session as commencing on the 1st of May, and ending on the 31st of July.

First Winter Session.-Chemistry; Anatomy and Physiology; Anatomical Demonstrations ; Materia Medica and Therapeutics.

First Summer Session.-Botany ; and such other branches of study as may improve the student's general education.

Second Winter Session.-Anatomy and Physiology; Anatomical Demonstrations ; Dissections ; Principles and Practice of Medicine; Medical Practice of an Hospital.

Second Summer Session.-Botany, if not attended during the First Summer Session; Midwifery and Diseases of Women and Children; Forensic Medicine ; Medical Practice of an Hospital.

Third Winter Session.-Dissections; Principles and Practice of Medicine; Midwifery, with attendance on cases; Medical Practice of an Hospital or Dispensary.

The student is required to attend the medical practice of a recognized hospital, from the commencement of the Second Winter to the terminamination of the Second Summer Session, and from time to time to the end of the Third Winter Ses$n$, at an hos pital or recognized dispensary.
The sessional course of instruction in each respective subject of study is to consist of noty tess than the following number of lectures, viz. -100 on Chemistry ; 100 on Materia Medica and Therapeutics; 100 on the Principles and Practice of Medicine; 60 on Midwifery and the Diseases of Women and Children; 50 on Forensic Medicine; 50 on Botany.

The number of lectures on anatomy and physio$\operatorname{logy}$, and of anatomical demonstrations, must be in conformity with the regulations of the Royal College of Surgeons of London on these subjects. The lectures required in each course respectively must be given on separate days. Students, when they present themselves for examination, must bring testimonials of having received instruction in practical chemistry during their attendance upon the lectures on chemistry, materia medica, or forensic medicine; and also of having attended a full course of clinical lectures, and such instruction in morbid artatomy as may be afforded them during their attendance at an hospital. Every student will be required to produce proof of having dissected the whole of the body, once at least.

\section{COURSE OF CLINICAL LECTURES}

ON

\section{SURGICAL DISEASES,}

DELIVERED AT THE HOSPITAL OF LA CHARITE'.

\author{
BY PROFESSOR VELPEAU.
}

LECTURE XI.

\section{PERMANENT CONTRACTION OF THE FINGERS.}

Gentekmen,-Permanent flexion or contraction of the fingers depends on a great number of causes ; it may arise from wounds, paralysis of the extensor muscles, anchylosis of the joints, tumors, shortening of the tendons, irregular cicatrices, \&c. On the present occasion, however, I wish to direct your notice to that form which depends on contraetion of the palmar fascia, or on the formation of fibrous bands extending from the palm of the hand to the fingers, and binding down the latter in their irregular position.

Before the remarks published in 1831, by Dupuytren, followed up by those of MM. Lemoine, Mandet, Vidal, Goyraud, \&c., permanent contraction of the fingers had not been much noticed by surgeons. Boyer alludes to the affection under the name of crispatura tendinum: Sir Astley Cooper, also, speaks of permanent retraction of the fingers and toes, which he attributes to contraction of the sheaths of the tendons or of the palmar and plantar aponeuroses. Dupuytren has clearly shown that the tendons are seldom engaged in this affection, but he has not so evidently demonstrated that it depends on induration, or shortening of one or more bands of the palmar fascia.

The disease now under consideration is charaeterised by the formation of certain bands or chords, which are elevated beneath the skin, and extend along a considerable portion of the palmar sarface 